\title{
The Effect of Extrusion Conditions and the Use of a Compatibilizer in the Crystallization of PBT/ABS Blends
}

\author{
José Donato Ambrósio ${ }^{\mathrm{a}, \mathrm{b} *}$, Luiz Antonio Pessan ${ }^{\mathrm{a}, \mathrm{c}}$, Harumi Otaguro , \\ Marcelo Aparecido Chinelatto $^{\mathrm{d}}$, Elias Hage Junior ${ }^{\mathrm{a}, \mathrm{c}}$

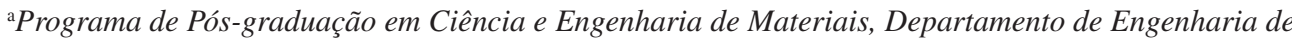 \\ Materiais, Universidade Federal de São Carlos - UFSCar, Rod. Washington Luis, Km 235, \\ CEP 13565-905, São Carlos, SP, Brasil \\ ${ }^{\mathrm{b}}$ Departamento de Engenharia de Materiais, Centro de Caracterização e Desenvolvimento de Materiais, \\ Universidade Federal de São Carlos - UFSCar, Rod. Washington Luis, Km 235, \\ CEP 13565-905, São Carlos, SP, Brasil \\ ${ }^{\mathrm{c}}$ Departamento de Engenharia de Materiais, Universidade Federal de São Carlos - UFSCar, \\ Rod. Washington Luis, Km 235, CEP 13565-905, São Carlos, SP, Brasil \\ ${ }^{\mathrm{d}}$ Departamento de Engenharia de Materiais, Universidade de São Paulo - USP, \\ Av. Trabalhador São Carlense, 4000, CEP 13560-970, São Carlos, SP, Brasil
}

Received: October 29, 2012; Revised: April 7, 2013

\begin{abstract}
Poly(butylene terephthalate) (PBT)/ acrylonitrile-butadiene-styrene (ABS) terpolymer blends were prepared in a twin screw extruder and the use of methyl methacrylate-glycidyl methacrylate-ethyl acrylate (MGE) terpolymer as compatibilization additive was evaluated. The effect of different screw profiles and mixing conditions were evaluated on the crystallization of the blends. Differential scanning calorimetry (DSC) was used to evaluate melting and crystallization behaviors of the PBT/ABS blends. The binary PBT/ABS blend has shown a double melting peak when cooled at lower cooling rates, mainly due to its melt-recrystallization during the heating up step. ABS has not affected the melting characteristics of neat PBT. The presence of MGE, as a reactive compatibilizer, in the PBT/ABS blends has reduced its heat of fusion and has partially inhibited its melt-recrystallization under heating. As result, it has prevented the occurrence of double melting peak. The epoxy functional groups of the MGE may react in situ to the carbonyls and hydroxyls end groups of the PBT molecules, thereby hindering the mobility of PBT molecules during the crystallization process due to its grafting to the compatibilizer molecules. The melt mixed blends prepared at lower feeding rate have shown a higher degree of crystallinity for the PBT/ABS blend, probably due to degradation of PBT caused by longer residence time in the extruder. The highest shear stress imposed to the blends at higher screw speed increased the degree of crystallinity of PBT, also due to its degradation.
\end{abstract}

Keywords: PBT/ABS blend, DSC, melt-recrystallization, double melting peak, twin screw extrusion

\section{Introduction}

Poly(butylene terephthalate) (PBT) is an engineering thermoplastic that combines desired characteristics such as: stiffness, hardness, abrasion resistance, solvent resistance, and electrical insulation. It is widely used to produce injection molded and extruded parts. Because PBT is a semi-crystalline polymer, its properties depend strongly on its degree of crystallinity, and the processing conditions which it is submitted.

Studies of melt behavior of PBT by DSC have shown that there is a double melting peak under heating ${ }^{1,2}$. The structure and morphology of PBT crystals are discussed extensively in the literature ${ }^{3-5}$. There are two types of crystalline structures for PBT, which have triclinic unit cells. Both $\alpha$ and $\beta$ crystalline phases have been detected for PBT, while $\beta$ phase is developed only under special process

*e-mail: donato@ccdm.ufscar.br conditions, i. e., under application of stress on non-oriented crystals $^{6}$. When a PBT sample crystallizes from the melt, it shows two different types of spherulites, one showing a normal Maltese cross and another one showing a Maltese cross rotated $45^{\circ}$ relative to normal position ${ }^{7}$, both with the same type $\alpha$ crystalline structure.

For a semicrystalline PBT, a large fraction of the noncrystalline material behaves as stiff amorphous domains at room temperature and a partial devitrification of those domains occurs between $40{ }^{\circ} \mathrm{C}$ and $50{ }^{\circ} \mathrm{C}$, depending on the crystallization conditions ${ }^{8}$. The temperature at which the rest of the amorphous phase stops to be vitreous has not yet been established, but it may be situated in the temperature range in which melting occurs. It is probably below $215^{\circ} \mathrm{C}$. In that condition the amorphous phase becomes not totally mobile and a complete devitrification occurs close to the temperature of the first melting peak under heating. 
Modulated DSC studies ${ }^{8}$ found that when PBT is submitted to a long time heat treatment in the range of temperatures close to the first endothermic melting peak, i.e., $216^{\circ} \mathrm{C}$, the crystalline structure remains imperfect under cold crystallization. The crystallization would be favored due to kinetic factors, however they are highly metastable, and their organization into more stable structures would seem impossible at temperatures below $215{ }^{\circ} \mathrm{C}$. Thus, when PBT is held for some time at temperatures in the order of $215^{\circ} \mathrm{C}$, whether through isothermal melting or at low heating rates, the initially imperfect structures are able to reach a better order and, hence, to recrystallize under heating, similar to a cold crystallization. Based on PBT crystalline phase changes in morphology during its melting, under a polarized light microscope coupled to a depolarized light intensity meter ${ }^{9}$, it was possible to observe that the spherulitic superstructure developed during isothermal melting are not modified until the polymer complete melting is end. That may be the reason why the double melting peak, commonly observed for PBT, is not originated from the presence of different spherulitic structures with particular thermal stabilities, but to melt-recrystallization.

Despite of some important characteristics of PBT, as mentioned earlier, its notch sensitivity to applied stress may lead PBT to break through a brittle failure. That frequently occurs when PBT notched specimens are tested under impact. In order to decrease its notch sensitivity and improve its toughness, different tough modifiers materials have been blended to $\mathrm{PBT}^{10-14}$. Acrylonitrilebutadiene-styrene (ABS) terpolymer has been successfully used to tough $\mathrm{PBT}^{15-21}$. As consequence, PBT/ ABS blends usually have high toughness and low ductile brittle transition temperatures ${ }^{15}$. However, those blends may show unstable phase morphology, since under quiescent melt conditions the ABS domains may coalesce, which leads to a worsening of the impact properties. To stabilize the morphology and to enhance toughness for PBT/ABS blends, it is necessary to compatibilize it with reactive compounds such as acrylic copolymers. MGE terpolymer synthesized from methyl methacrylate (MMA), glycidyl methacrylate (GMA) and ethyl acrylate (EA) has been used as compatibilizer for PBT/ABS blends ${ }^{16-18}$. The epoxy groups of the GMA units from the MGE molecules reacts in situ with the carbonyl and hydroxyl end groups of the PBT molecules during the melt mixing, while the EA-MMA-rich segments of the resulting PBT-g-GMA-EA-MMA grafted molecules become miscible with the SAN phase of ABS. As result, the grafted molecules will be located in the PBT/SAN (rich phase from $\mathrm{ABS}$ ) interface region, thereby leading to better interfacial coupling for the PBT/ABS blend.

One of the most usual ways to prepare polymer blends in the molten state is through twin screw extrusion ${ }^{22}$. Modulated co-rotated twin screw extruders are more adequate to prepare those blends because the screw profile can be designed to promote the best blending conditions. The blend phase morphology and its performance depend mainly on the screw profile, temperature profile, feeding rate and screw speed. Those extrusion parameters can be changed and also may affect the rheological and thermal properties of the blends and of their individual components during its preparation. The correlation between some of the extrusion parameters and the blend thermal properties has not been extensively explored. The polymer blend thermal properties can be used to analyze its crystallization behavior. Therefore, the melt mixing processing conditions for the polymer blend preparation may affect the polymer blend crystalline phase characteristics. For PBT/ABS blends the dispersed domains of ABS may break and coalesce simultaneously during melt mixing. That depends also on the processing conditions which can make PBT suffer degradation due to strong shear stress and high temperatures.

Studies on thermal degradation of $\mathrm{PBT}^{23}$, analyzed by thermogravimetry (TGA) and FTIR, have shown that $\mathrm{CO}_{2}$ and $\mathrm{H}_{2} \mathrm{O}$ are liberated as degradation sub-products up to $240{ }^{\circ} \mathrm{C}$ and above that temperature the PBT could be strongly degraded, resulting in decrease in molecular weight and increase in the $\mathrm{COOH}$ end groups content for the PBT molecules, and formation of various others compounds ${ }^{23-26}$.

In this context, much effort has focused on understanding and optimizing how the polymer blend mixing process in twin screw extruder and the process parameters such as: feed rate, screw rotation, residence time and temperature of the melt, affect the blend morphology and the crystallinity of the crystallizable component.

Therefore, the main objective of the present study is to contribute to the knowledge about the correlation between the melt mixing processing conditions and the crystallization of PBT/ABS blends compatibized by MGE, characterized by DSC.

\section{Experimental}

\subsection{Material}

The PBT and the ABS used in this study were provided by Sabic Innovative Plastics South America, as Valox 315 and Cycolac 36360, respectively. The PBT Valox 315 has a melt flow index of $6.3 \mathrm{~g} / 10 \mathrm{~min}$ when measured at $250{ }^{\circ} \mathrm{C}$ under a load of $1.20 \mathrm{Kg}$, and its average numerical molar mass measured by solution viscosimetry is about 42,000 g/mol. The ABS Cycolac 36360 composition was quantitatively characterized by FTIR as $51 \mathrm{wt} \%$ butadiene, $36 \mathrm{wt} \%$ styrene and $13 \mathrm{wt} \%$ acrylonitrile.

The MGE terpolymer used as compatibilizer for the PBT/ABS blends was synthesized by bulk copolymerization using the following composition: methyl methacrylate (MMA) (88 wt\%), glycidyl methacrylate (GMA) (10 wt\%) and ethyl acrylate (EA) $(2 \mathrm{wt} \%)^{27,28}$. EA was used mainly to enhance the thermal stability and prevent unzipping degradation to the final copolymer during melt mixing. Copolymerization was performed under high conversion rate and the resulting copolymer was essentially random, with numerical and weight average molecular weight equal to $12,000 \mathrm{~g} / \mathrm{mol}$ and $53,500 \mathrm{~g} / \mathrm{mol}$, respectively. MMA was first distilled under vacuum at $35^{\circ} \mathrm{C}$, while the GMA more than $97 \%$ pure was used as supplied. Azobisisobutironitrila (AIBN) was used as initiator. It was purified by recrystallization in ethanol. The acrylic monomers with $3.5 \mathrm{wt} \%$ of AIBN were mixed in sealed polypropylene bags and left in a water bath at $60{ }^{\circ} \mathrm{C}$ 
for one hour. MGE was then cryogenically milled and dried in vacuum oven at $50{ }^{\circ} \mathrm{C}$ for 5 days. Poly (methyl methacrylate) (PMMA) was used to replace the MGE in the blend to obtain the PBT/ABS/PMMA blends without any in situ compatibilization reaction. PMMA was provided by UNIGEL as Acrigel with melt flow index of $4.6 \mathrm{~g} / 10 \mathrm{~min}$.

\subsection{Blends preparation}

The PBT/ABS blends were prepared using a Werner \& Pfleiderer ZSK-30 intermeshing co-rotating twin screw extruder (ICTSE) with $30 \mathrm{~mm}$ screw diameter and L/D=34. The thermal profile chosen for the extruder from the feeding zone to the extrusion die started as $270{ }^{\circ} \mathrm{C}$ and ended up as $240{ }^{\circ} \mathrm{C}$. The screw profiles for the blends preparation are shown in Figure 1. Two different profiles were chosen to prepare the PBT/ABS blends. Both screw profiles are similar while the main difference stays in the second kneading block downstream designed to promote better melt mixing. Screw profile (a) in the Figure 1 has in a large kneading blocks (KB) zone with $4 \mathrm{~KB}$ elements with each one designated as KB45/5/42 each. The digit 45 represents the $45^{\circ}$ angle between the discs in the element, while 5 represents the number of discs in the element and 42 represents how large in millimeters is the element. Screw profile (b), on the other hand, has a shorter kneading blocks zone with smaller $4 \mathrm{~KB}$ elements designated as KB45/5/14 each, i. e., 5 discs $14 \mathrm{~mm}$ thick each with $45^{\circ}$ between them . As result, the main difference between both screw profiles is the last kneading blocks zone, where the screw profile (a) has a larger KB section. Screw profile (a) may lead to an intense shear for the blends melt mixing. Narrower kneading blocks always generate less shear stress during melt mixing, while wider kneading blocks (KBs) allow higher shear stress. Depending on the other extrusion parameters, such as; temperature profile and screw rpm, wider KBs may lead to strong molecular degradation to the blend components. In addition, those wider KBs may also give higher viscous heating energy to increase the rate of the in situ reaction during melt mixing.

The binary and ternary, compatibilized, PBT/ABS blends were prepared through 70/30 and 65/30/5 by weight compositions, respectively. MGE and PMMA were used in a proportion of $5 \mathrm{wt} \%$, while the feeding rates were $7.0 \mathrm{~kg} / \mathrm{h}$ and $3.5 \mathrm{~kg} / \mathrm{h}$ and the screw rotation speeds were chosen to be 120 and $240 \mathrm{rpm}$, using two different screw profiles, as indicated in Figure 1. Based on these parameters, the experimental design is shown in Table 1, which identifies the samples of non-compatibilized, binary, PBT/ABS blends with letters $\mathrm{NCB}$ and the ones compatibilized with letters CB. All samples tested in the DSC were taken from strip specimens as extruded.

\subsection{DSC thermal characterization}

DSC analysis of the samples was carried out in a Mettler Toledo calorimeter model 822e. The DSC curves were obtained using a closed aluminum pan, under dry

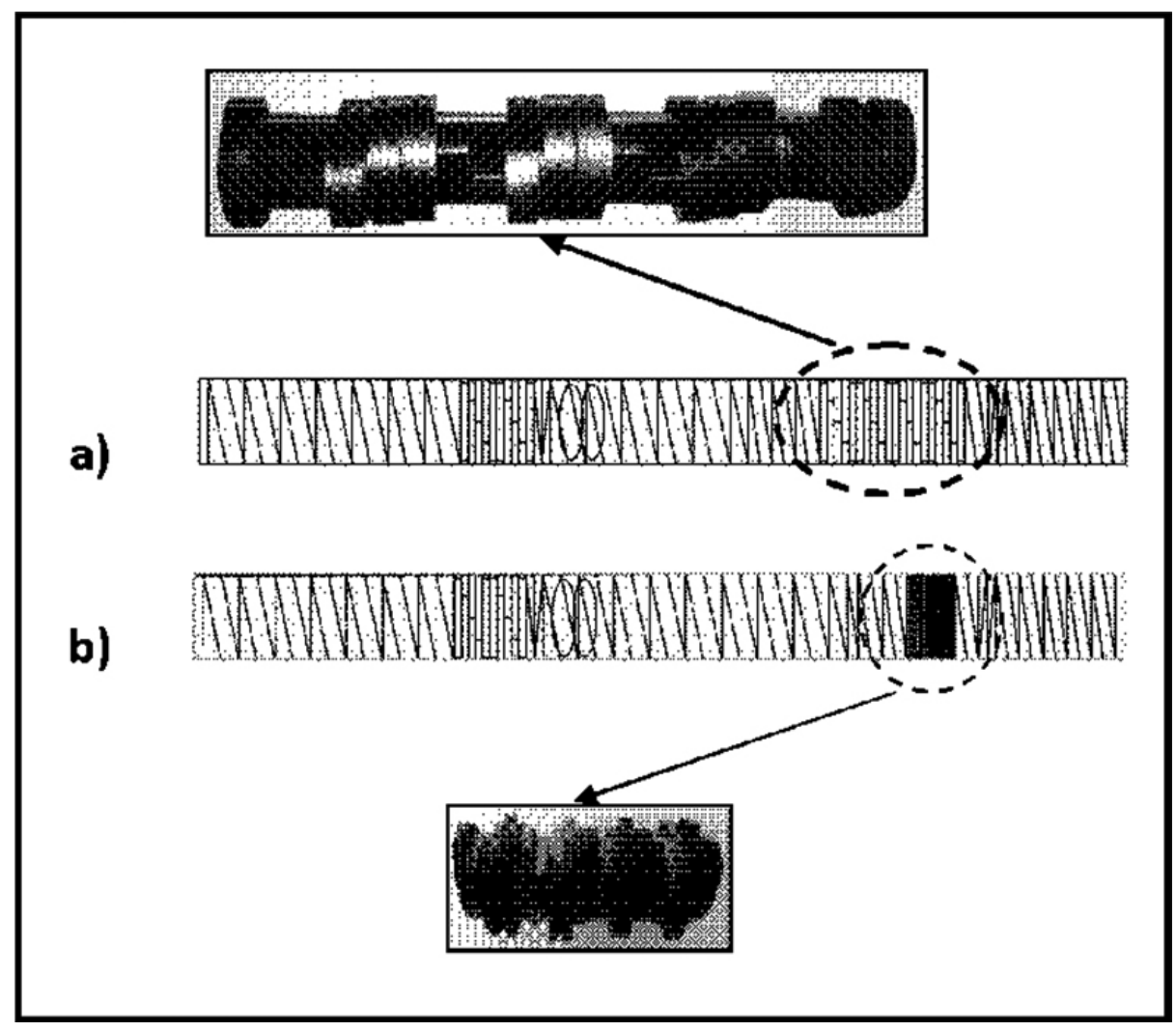

Figure 1. Profile of the twin extrusion screws used for the PBT/ABS blends preparation, where (a) screw type 4KB45/5/42 and (b) screw type 4KB45/5/14. 
nitrogen continuous fluxing gas. The neat PBT and all the blend samples were first heated to $250{ }^{\circ} \mathrm{C}$, followed by a cooling step down to $30^{\circ} \mathrm{C}$ temperature and then reheated up to $250{ }^{\circ} \mathrm{C}$, at heating and cooling rates of $10^{\circ} \mathrm{C} / \mathrm{min}$ and $-10^{\circ} \mathrm{C} / \mathrm{min}$, respectively. All the measured cooling and heating enthalpies were corrected for the PBT amounts in the blends.

\subsection{Capillary rheometry characterization}

The capillary rheometry analyses were performed at $250{ }^{\circ} \mathrm{C}$ in a Instron Rheometer, with a $0.762 \mathrm{~mm}$ diameter (D) and $\mathrm{L} / \mathrm{D}=33$ capillary die, and shear rates ranging from $100 \mathrm{~s}^{-1}$ to $10,000 \mathrm{~s}^{-1}$ have been used.

\section{Results and Discussion}

\subsection{Analysis of thermal behavior of the PBT through the DSC}

Figure 2 shows the DSC thermograms for neat PBT as extruded and after being crystallized from the melt. The melting and crystallization temperatures were chosen as the peak temperatures. Tm 1 represents the melting temperature during the first heating step, while Tm2L and $\mathrm{Tm} 2 \mathrm{H}$ represent the melting temperatures for the double peak during the second heating step. Tc represents the crystallization temperature measured under cooling in the DSC. $\Delta \mathrm{H} 1$ and $\Delta \mathrm{H} 2$ represent the heat of fusion for

Table 1. Sample identification, compatibilizer content and extrusion processing parameters used to obtain PBT/ABS blends.

\begin{tabular}{lcccc}
\hline Sample & $\begin{array}{c}\text { Percent of MGE } \\
{[\mathbf{w t} \%]}\end{array}$ & $\begin{array}{c}\text { Screw Speed } \\
{[\mathbf{r p m}]}\end{array}$ & $\begin{array}{c}\text { Feeding Rate } \\
{[\mathbf{k g} / \mathbf{h}]}\end{array}$ & Screw Profile \\
\hline PBT & 0 & 120 & 7.0 & $4 \mathrm{~KB} 45 / 5 / 42$ \\
NCB1 & 0 & 120 & 7.0 & $4 \mathrm{~KB} 45 / 5 / 42$ \\
NCB2 & 0 & 120 & 7.0 & $4 \mathrm{~KB} 45 / 5 / 14$ \\
CB1 & 5 & 120 & 7.0 & $4 \mathrm{~KB} 45 / 5 / 42$ \\
CB2 & 5 & 120 & 3.5 & $4 \mathrm{~KB} 45 / 5 / 42$ \\
CB3 & 5 & 120 & 7.0 & $4 \mathrm{~KB} 45 / 5 / 14$ \\
CB4 & 5 & 120 & 3.5 & $4 \mathrm{~KB} 45 / 5 / 14$ \\
CB5 & 5 & 240 & 7.0 & $4 \mathrm{~KB} 45 / 5 / 42$ \\
CB6 & 5 & 240 & 7.0 & $4 \mathrm{~KB} 45 / 5 / 14$ \\
\hline
\end{tabular}
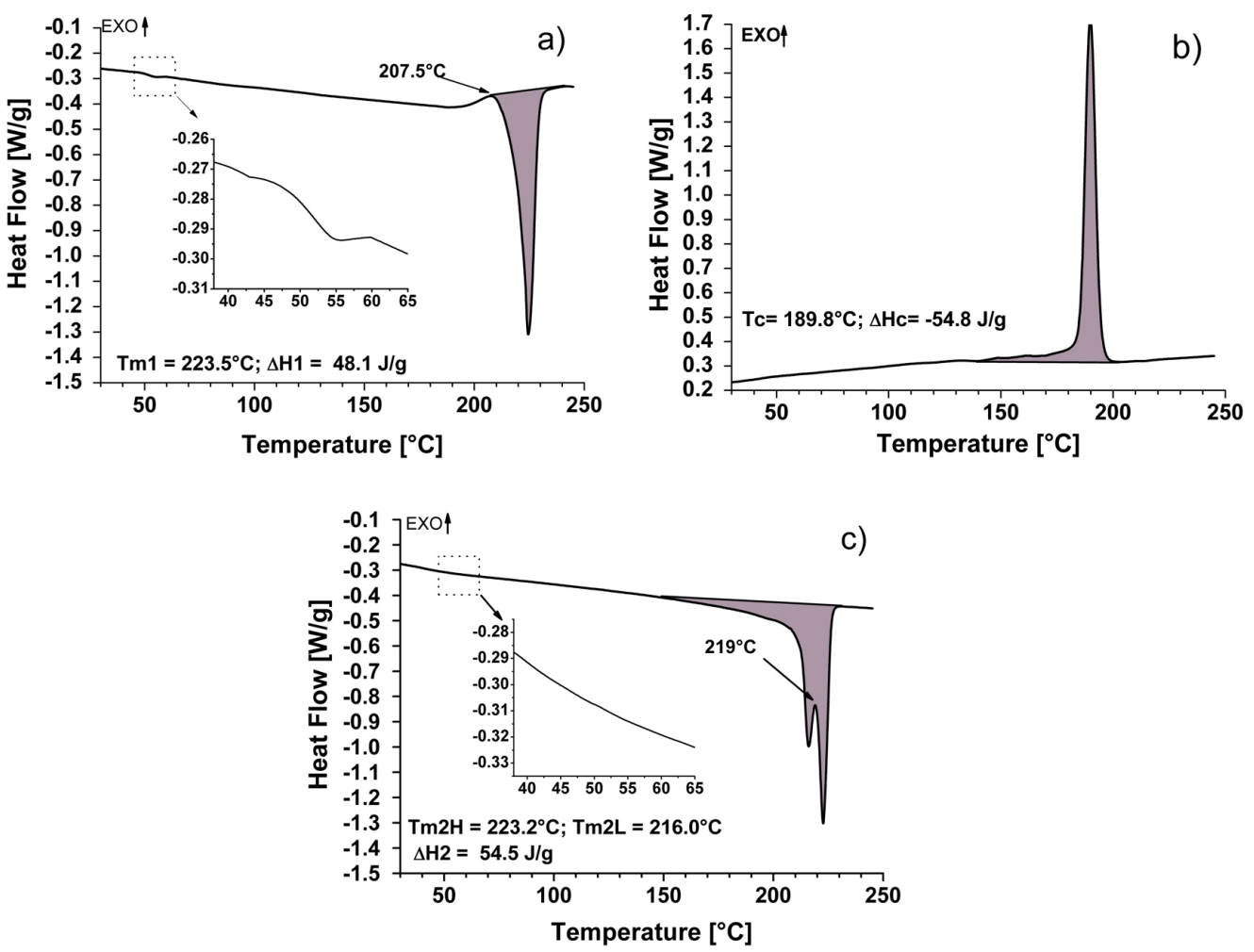

Figure 2. DSC thermograms of the neat PBT after extrusion, where: (a) First heating step, (b) Cooling step, (c) Second heating step. 
the first and second heating step, respectively, while $\Delta \mathrm{Hc}$ represents the heat of crystallization under cooling. The glass transition region has been expanded in the curves to visualize better $\mathrm{Tg}$. Figure $2 \mathrm{a}$ shows the first heating cycle that reveals the thermal and shear history at which PBT was submitted in the extruder and also to the quick cooling in water just after leaving the extruder dies. The thermogram for PBT, under cooling in the DSC, in Figure $2 b$ shows a crystallization peak temperature close to $190^{\circ} \mathrm{C}$. It is known that the crystallization temperature depends on the cooling rate. Studies of the kinetics of crystallization for several types of thermoplastic polyesters were done to simulate the injection molding ${ }^{29}$. It was found that the PBT crystallization temperature was drastically reduced when the cooling rate was increased. In those studies, the crystallization temperature dropped by about $8{ }^{\circ} \mathrm{C}$ when the cooling rate was increased from $-10{ }^{\circ} \mathrm{C} / \mathrm{min}$ to $-20^{\circ} \mathrm{C} / \mathrm{min}$.

The thermogram for the second heating step also depends on the cooling rate set in the DSC. In addition, it shows the PBT melting behavior without the influences of the shear and thermal history from the extrusion step. As the extrusion process may result irreversible chemical modifications due to possible PBT degradation, those results are important to evaluate the influence of the extrusion mixing process on the crystallization behavior of PBT. Those observations may also be applied to the PBT/ABS blends.

The heat of fusion for $100 \%$ crystalline PBT has been assumed as $140 \mathrm{~J} / \mathrm{g}^{[30]}$. Thus, the thermogram of the second heating in Figure 2c for the neat PBT, which was cooled in the DSC at a controlled rate of $-10{ }^{\circ} \mathrm{C} / \mathrm{min}$, shows a degree of crystallinity of approximately $40 \%$. The glass transition temperature ( $\mathrm{Tg}$ ) observed during the first heating step for PBT in Figure $2 \mathrm{a}$ is approximately $50{ }^{\circ} \mathrm{C}$. The glass transition could not be easily observed during the second heating step. It could not be noted even with the curve expansion, as observed in Figure 2c. The higher heat of fusion for the second heating step as compared to the first heating one indicates that as the PBT crystallinity has increased the amorphous content was reduced. Thus it became more difficult to observe $\mathrm{Tg}$ transition in the second heating step. Usually the DSC sensitivity is not sufficient to detect the glass transition for lower amorphous phase content for semi-crystalline thermoplastic.

Comparing the thermograms of the first and second heating steps in Figures 2, it can be noted that, while in the first heating step, as observed in Figure 2a, there is a single endothermic melting peak, for the second heating step, Figure $2 \mathrm{c}$, there is a double melting peak and a pseudoexothermic peak at $219.3{ }^{\circ} \mathrm{C}$. The difference between these two DSC thermograms was the cooling rate at which the PBT was subjected before both heating steps. The temperature of the molten PBT at the exit of the extruder die was $265^{\circ} \mathrm{C}$, and it was quickly cooled in water just after leaving the die. In about one minute after this procedure, the PBT has reached the room temperature, which was approximately $35{ }^{\circ} \mathrm{C}$. Therefore, the cooling rate after extrusion was about 23 times faster than in the DSC, which was $10{ }^{\circ} \mathrm{C} / \mathrm{min}$. Although a double melting peak was not observed in the first heating step, it can be noted the presence of a small exothermic peak at $207.5{ }^{\circ} \mathrm{C}$. That peak is considered to be equivalent to a pseudo-exothermic one that has occurred in the second heating step at $219.3{ }^{\circ} \mathrm{C}$. Due to the faster cooling that PBT was subjected to before the first heating step the temperature of the exothermic peak was reduced for approximately $12{ }^{\circ} \mathrm{C}$, inhibiting the occurrence of the double melting peak in the first heating ${ }^{2}$.

Several authors have explained the occurrence of the double melting peak for PBT through the melt-recrystallization model ${ }^{2,31-33}$. That model suggests that the lower-temperature and higher-temperature for the double peak in the DSC curve are attributable to the melting of some amount of original crystals and the melting of crystals formed through the melt-recrystallization process during a heating scan, respectively. The meltrecrystallization model suggests that small and/or imperfect crystals change successively to more stable crystals through the melt-recrystallization mechanism. That is, melting and recrystallization are competitive during the heating process. The higher-temperature endothermic peak is shown when the rate of melting overwhelms that of the recrystallization. On the other hand, the lower temperature endothermic peak happens when the rate of recrystallization overwhelms that of the melting. Accordingly, the melt-recrystallization behavior, especially an increase in crystallinity, is considered to be substantial in the melting process ${ }^{33}$.

Studies ${ }^{33}$ using wide-angle X-ray diffraction (WAXD) and DSC have shown that during cooling at a controlled rate in the DSC, only a single exothermic peak appeared on the DSC thermogram, suggesting a single modal distribution of the size of crystallites formed during the cooling process. The X-ray diffraction pattern had not shown any change on it during the heating process of the PBT in DSC, thereby concluding that its crystal structure had not modified during the melting process. The $\mathrm{X}$-ray diffraction peak intensities decreased gradually up to $200{ }^{\circ} \mathrm{C}$, mainly relate to (010). On the other hand, as the PBT was further heat up the (010) intensity became higher again at $216^{\circ} \mathrm{C}$. According to the authors $^{33}$, that increase in the X-ray diffraction intensity at that temperature would be concrete proof of recrystallization during the melting process.

Figure 3 shows PBT/ABS blends melting behavior observed during the DSC experiments. In the first heating step, as shown in Figure 3a, the binary PBT/ABS blend obtained directly from the extruded samples has shown only a well single defined melting peak, due to melting of the PBT crystalline phase in the blend. On the other hand, the second heating step for the same blend, Figure 3b, has shown a double melting peak. Both melting peak types have already been observed for the neat PBT as seen in Figure 2c. Apparently the presence of ABS has not affected the binary PBT/ABS melting peaks behavior, as already observed before $^{34}$. No melting temperature depression was observed for the PBT crystalline phase, which would be a strong indication of the immiscibility of the blend's components, according to the criterion of established by Runt ${ }^{35}$. By adding MGE reactive compatibilizer to the PBT/ABS blend it was not observed any significant change in the melting peak shape and temperature for the first heating step, as compared in Figure 3a. However, the heat of fusion, $\Delta \mathrm{H} 1$, was reduced by almost $20 \%$ during that heating step. The 

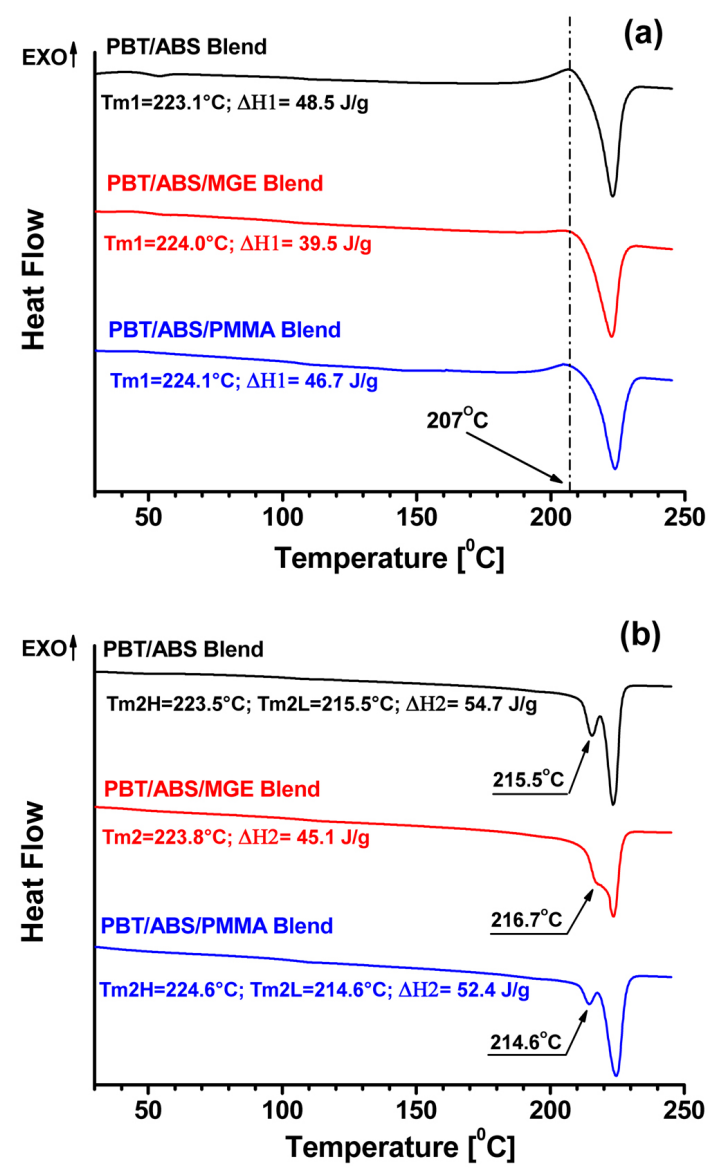

Figure 3. DSC thermograms of the PBT/ABS blends after extrusion, where: (a) 1st heating thermograms, (b) Second heating thermograms.

in situ reactive compatibilization promoted by the MGE terpolymer leads to some PBT molecules grafted to MGE molecules. As results, the grafted PBT molecules cannot crystallizes as well as the regular PBT molecules, thereby decreasing the amount of the PBT crystalline phase in the blend. Therefore, the heating of fusion would be reduced for compatibilized blends.

MGE has been replaced by polymethyl methacrylate (PMMA) to eliminate any possible in situ reaction with PBT molecules. The first heating step melting behavior for the PBT/ABS/PMMA blend can be observed in Figure 3a. Apparently no significant changes were observed nor for the melting peak temperature Tm1 nor for the heat of fusion $\Delta \mathrm{H} 1$, when compared to the binary PBT/ABS blend. The molecular structure of PMMA is similar to the MGE copolymer, however it has no GMA units within its molecules which have epoxy functional groups to react with the PBT molecules. The grafted PBT-g-MGE molecules could not fit in the PBT crystal structure because the MGE segments are completely amorphous. Thus, the PMMA molecules cannot reacts with the PBT molecules, thereby allowing them to be free to crystallize as neat PBT in the blend.
Figure $3 \mathrm{~b}$ shows the double melting peak observed in the binary PBT/ABS blend in the second heating step after slow cooling in the DSC, which has already been discussed previously for neat PBT. As can be observed the presence of ABS did not cause significant changes in melting behavior of the PBT compared to neat PBT (Figure 2c), i.e., the temperatures of the double melting peak and the heat of fusion for PBT crystalline phase remained almost unchanged with the addition of ABS. On the other hand, MGE has caused almost a suppression of the Tm2L for the reactive compatibilized PBT/ABS blend. The double melting peak has become a shoulder at lower temperature for the main melting peak. In addition the heat of fusion during the second heating step for PBT/ABS/MGE has decreased by the same percentage as was observed in the first heating step. The grafted PBT molecules generated by the in situ reaction with MGE molecules during the melt blending extrusion have prevented part of the PBT phase crystallization during the cooling step in the DSC. Once again MGE was replaced by PMMA in the ternary PBT/ABS blend to eliminate any in situ compatibilization reaction. The double melting peak was quite similar to the one for binary PBT/ABS blend, as observed in Figure 3b. The heat of fusion for the PBT/ABS/PMMA blend was also very close to the one for binary PBT/ABS blend. Thus, it could be confirmed that MGE has reacted with $\mathrm{PBT}$ rich phase.

\subsection{Influence of processing parameters on the melting and crystallization of the PBT/ABS blends}

Table 2 shows the influence of the process parameter (screw speed, feeding rate and screw profile) on the thermal behavior of the binary and compatibilized PBT/ABS blends.

The first heat step has provided information about the influence of the blending parameters under extrusion on the thermal behavior of those blends, while the second heat step has revealed the intrinsic thermal behavior of it, which has been cooled in DSC at $-10^{\circ} \mathrm{C} / \mathrm{min}$ under nitrogen atmosphere. Thus, the second heat could be really useful to show essential modifications on the melting behavior of the blends due to the blending extrusion. It is well known that the process parameters may have strong influence on the mechanical behavior of blends ${ }^{28}$.

For the uncompatibilized binary PBT/ABS blends the influence of the screw profile in the extruder on its thermal behavior was not significant, as comparing samples NCB1 and NCB2. During the first heating step the Tm1 and $\Delta \mathrm{Hm} 1$ values has shown almost no difference. The main difference was shown in the Tc values, where blend prepared using a large kneading block (KB) has shown higher crystallization temperature. Those values are similar to the ones for neat PBT, as shown in Figure 2b, which was extruded with the same screw profile and at same screw speed and feeding rate (Table 1). Therefore, the ABS component has not changed the melting and the crystallization behaviors of PBT at the same blending conditions. The blending conditions have changed the thermal behavior of the compatibilized PBT/ABS blends. The screw profile has affected the DSC thermal properties for PBT/ABS/MGE blends when they were blended at same screw speed and feeding rate. Samples 
Table 2. Influence of the processing parameters on the melting behavior of the PBT/ABS blends prepared by extrusion.

\begin{tabular}{|c|c|c|c|c|c|c|c|c|c|c|}
\hline \multirow{3}{*}{$\begin{array}{c}\text { PBT/ABS } \\
\text { Blend } \\
\text { Sample }\end{array}$} & \multirow{3}{*}{$\begin{array}{c}\text { MGE } \\
\text { [wt\%] }\end{array}$} & \multirow{3}{*}{$\begin{array}{l}\text { Screw } \\
\text { Speed } \\
{[\text { rpm] }}\end{array}$} & \multirow{3}{*}{$\begin{array}{c}\text { Feeding } \\
\text { Rate } \\
{[\mathbf{k g} / \mathbf{h}]}\end{array}$} & \multirow{3}{*}{$\begin{array}{l}\text { Screw } \\
\text { Profile }\end{array}$} & \multicolumn{2}{|c|}{$\mathbf{1}^{\text {st }}$ Heating } & \multicolumn{2}{|c|}{ Cooling } & \multicolumn{2}{|c|}{$2^{\text {nd }}$ Heating } \\
\hline & & & & & Tm1 & $\Delta \mathbf{H m 1}$ & Tc & $\Delta \mathbf{H c}$ & Tm2H & $\Delta \mathbf{H m} 2$ \\
\hline & & & & & {$\left[{ }^{\circ} \mathbf{C}\right]$} & {$[\mathrm{J} / \mathrm{g}]$} & {$\left[{ }^{\circ} \mathbf{C}\right]$} & {$[\mathbf{J} / \mathbf{g}]$} & {$\left[{ }^{\circ} \mathbf{C}\right]$} & {$[\mathrm{J} / \mathrm{g}]$} \\
\hline NCB1 & 0 & 120 & 7.0 & $4 \mathrm{~KB} 45 / 5 / 42$ & 223.1 & 48.5 & 189.3 & -55.3 & 223.5 & 54.7 \\
\hline NCB2 & 0 & 120 & 7.0 & $4 \mathrm{~KB} 45 / 5 / 14$ & 224.5 & 48.0 & 185.9 & -54.2 & 224.1 & 53.8 \\
\hline CB1 & 5 & 120 & 7.0 & $4 \mathrm{~KB} 45 / 5 / 42$ & 224.0 & 39.5 & 188.7 & -42.3 & 223.8 & 45.1 \\
\hline $\mathrm{CB} 2$ & 5 & 120 & 3.5 & $4 \mathrm{~KB} 45 / 5 / 42$ & 225.2 & 51.2 & 187.9 & -58.2 & 225.1 & 58.6 \\
\hline CB3 & 5 & 120 & 7.0 & $4 \mathrm{~KB} 45 / 5 / 14$ & 225.4 & 42.4 & 185.8 & -48.6 & 226.1 & 47.0 \\
\hline CB4 & 5 & 120 & 3.5 & $4 \mathrm{~KB} 45 / 5 / 14$ & 224.9 & 52.3 & 186.9 & -58.1 & 225.2 & 58.6 \\
\hline CB5 & 5 & 240 & 7.0 & $4 \mathrm{~KB} 45 / 5 / 42$ & 225.8 & 46.8 & 191.1 & -53.0 & 225.9 & 52.9 \\
\hline CB6 & 5 & 240 & 7.0 & $4 \mathrm{~KB} 45 / 5 / 14$ & 225.7 & 43.3 & 189.9 & -51.0 & 225.2 & 52.1 \\
\hline
\end{tabular}
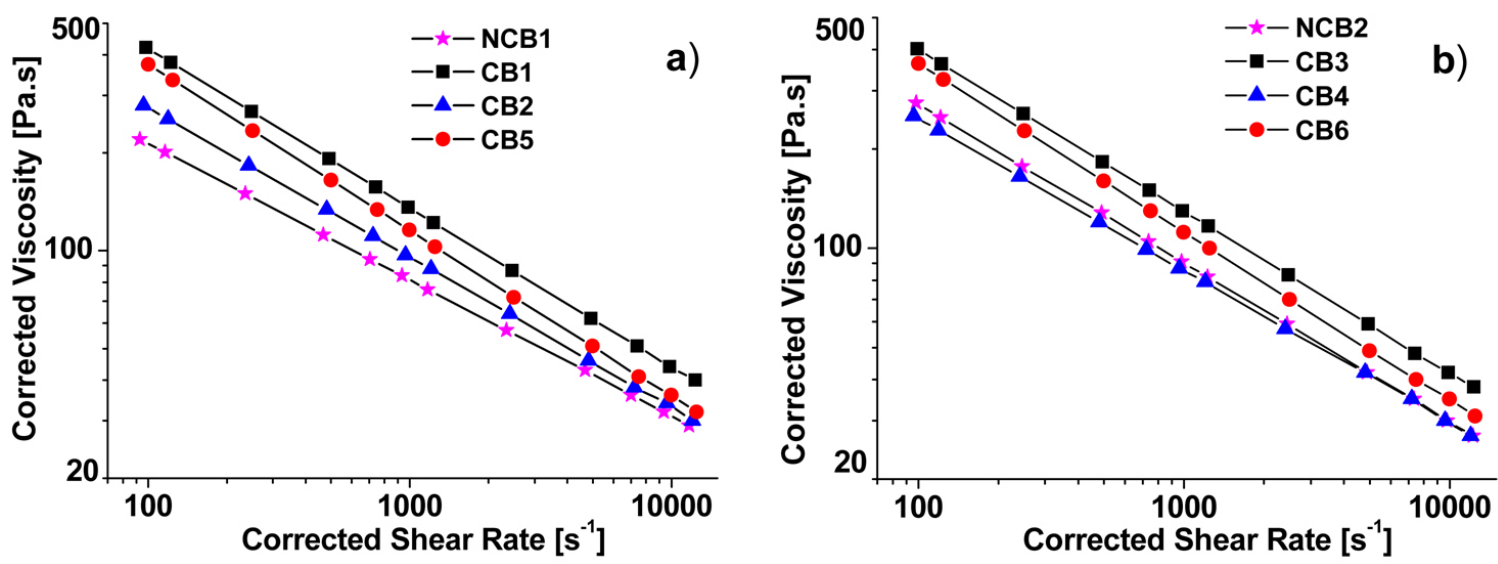

Figure 4. Shear viscosity as function of shear rate curves of the PBT/ABS blends: a) PBT/ABS blends prepared using the screw profile $4 \mathrm{~KB} 45 / 5 / 42$ and processing conditions NCB1, CB1, CB2 and CB5; b) PBT/ABS blends prepared using the screw profile 4KB45/5/14 and processing conditions NCB2, CB3, CB4 and CB6, all conditions according with Table 1.

$\mathrm{CB} 1$ and $\mathrm{CB} 3$ can be compared in Table 2 to check those differences. Larger KB has decrease the melting temperature in both heating steps. In addition, it has also shown smaller heat of fusion. On the other hand, larger KB has shown higher crystallization temperature than for the narrow one. Larger KB usually gives higher shear energy to the blend. The in situ reactive compatibilization due to the presence of MGE in the PBT/ABS blend has its kinetic affected by the increase of the shear energy, thereby leading to different molecular structure to the grafted PBT-MGE molecules. That change may modify the crystallization behavior of the PBT rich phase in the compatibilized blend. It seems that the CB1 molecules crystallize faster than CB3, however, it cannot reach the same level of crystallinity ${ }^{35}$. If the screw profile and speed are kept the same for larger and narrower $\mathrm{KBs}$, and the feeding rate is reduced the melting temperature was increased for both heating steps. In addition, the heats of fusion and for crystallization in the DSC have become well above compared to higher feeding rate. Those observations could be taken from the comparison among the samples $\mathrm{CB} 1$ vs $\mathrm{CB} 2$ and $\mathrm{CB} 3$ vs CB4 in Table 2. The screw channels become less filled during processing at lower feeding rates. As consequence, the pressure to transport the melted blend through the screws is lower, causing the blend to remain for longer residence time in the extruder. As the blends processed with $3.5 \mathrm{~kg} / \mathrm{h}$ remain longer inside the extruder it will be subjected to higher shear. Those processing conditions could lead to PBT rich phase molecular degradation, which usually occurs by chain scission $^{23}$. Therefore, PBT short chains would have higher mobility to crystallize at higher crystallinity content. When the PBT chains are degraded they become shorter with higher mobility, which becomes easier to adjust them in the crystalline pattern structure. That could be the main reason to allow higher heat of fusion during melting in the DSC.

Figure 4 shows the viscosity behavior for the PBT/ABS blends under capillary rheometry. All blends behave as pseudoplastic fluids, following the power law. In addition, the shear viscosity curves show lower viscosity values in the shear rate tested range for the uncompatibilized PBT/ABS. As MGE is added to the binary blend the viscosity is increased due to the grafting in situ compatibilizing reactions. Comparing the viscosity behavior for samples NCB1 and CB1 in Figure 4a it could be observed a big difference between them due only to the reactive compatibilization. Similar behavior was observed for samples NCB2 and CB3 as seen in Figure 4b. Therefore, the effect of the in situ reactive compatibilization in the 
viscosity was the same for both screw profiles. On the other hand, a decrease in the feeding rate down to $3.5 \mathrm{~kg} / \mathrm{h}$ has shown a strong decrease in the viscosity values comparing samples CB1 and CB2 in Figure 4a and samples CB3 and CB4 in Figure 4b. That must be a strong evidence of the blend degradation which confirms the supposing PBT rich phase degradation observed in the DSC due to the increase in heat of fusion. The effect of a change in the screw speed can be observed during the melting in the DSC, as seen in Table 2, as well as in the shear viscosity curves from Figure 4. Assuming similar screw profile and feeding rate and changing the screw speed from 120 to $240 \mathrm{rpm}$ samples CB1 and CB5 can be compared, as well as samples CB3 and CB6. From Table 2 it was also possible to note an increase in the heat of fusion and in the heat of crystallization for the heating cycle for both samples CB5 and CB6. As the screw speed is increased the blend molecules would be submitted to strong shear under melt mixing. In addition, the mixing temperature might rise up due to stronger viscous heating. As consequence, higher screw speed could also degradate PBT rich phase in the blends by molecular scission. From Figure 4 shear viscosity curves has shown a decrease in the viscosity values for samples $\mathrm{CB} 5$ and $\mathrm{CB} 6$, compared to $\mathrm{CB} 1$ and $\mathrm{CB} 3$, respectively, as a strong evidence of blend degradation. In both cases the PBT/ABS/MGE blends viscosity values for higher screw speed have stayed below than the lower speed.

\section{References}

1. Nichols ME and Robertson RE. The origin of multiple melting endotherms in the thermal analysis of polymers. Journal Polymer Science Part B: Polymer Physics. 1992; 30(3):305-307. http://dx.doi.org/10.1002/polb.1992.090300311

2. YasuniwaM,TsubakiharaSandMurakamiT.High-pressureDTA of poly(butylene terephthalate), poly(hexamethylene terephthalate), and poly(ethylene terephthalate). Journal Polymer Science Part B: Polymer Physics. 2000; 38(1):262- 272. http://dx.doi. org/10.1002/(SICI)1099-0488(20000101)38:1<262::AIDPOLB28>3.0.CO;2-5

3. Kim HG and Robertson RE. Multiple Melting Endotherms in Isothermally Melt-Crystallized Poly(butylene terephthalate). Journal Polymer Science Part B: Polymer Physics. 1998; 36(10):1757-1767. http://dx.doi.org/10.1002/ (SICI)1099-0488(19980730)36:10<1757::AID-

POLB17>3.0.CO;2-8

4. Li L and Jeu WH. Shear-Induced Crystallization of Poly(butylene terephthalate): A Real-Time Small-Angle X-ray Scattering Study. Macromolecules. 2004; 37(15):5646-5652. http://dx.doi.org/10.1021/ma0496145

5. Pyda M, Nowak-Pyda E, Heeg J, Huth H, Minakov AA, Di Lorenzo ML, Schick C et al. Melting and Crystallization of Poly(butylene terephthalate) by Temperature-Modulated and Superfast Calorimetry. Journal Polymer Science Part B: Polymer Physics. 2006; 44(9):1364-1377. http://dx.doi. org/10.1002/polb.20789

6. Di Lorenzo ML and Righetti MC. Crystallization of poly(butylene terephthalate). Polymer Engineering and Science. 2003; 43(12):1889-1894. http://dx.doi.org/10.1002/ pen. 10160

\section{Conclusions}

The melting behavior for PBT as extruded is different from when it is crystallized under controlled cooling rate in the DSC. A double melting peak is observed for PBT during a heating step after its crystallization under DSC cooling. ABS has not affected the PBT melting and crystallization behaviors when blended to it. MGE strongly affects the PBT/ABS blend melting and crystallization behaviors. It can prevent the double melting peak for PBT/ABS samples crystallized in the DSC.

The screw profile can affect the PBT/ABS blends thermal properties obtained in the DSC when larger kneading blocks $(\mathrm{KB})$ are used in the mixing screw section. That kind of KB may degradate the PBT rich crystalline phase by chain scission. Lower extrusion feeding rate may also degradate the PBT/ABS/MGE crystalline phase due to longer residence time during the mixing in the extruder. Those effects have increased the heat of fusion of the compatibilized blend. Higher screw speed has also degradated the PBT/ABS/MGE blend due to higher shear stresses and viscous heat imposed to the blend during the mixing step.

\section{Acknowledgments}

To Fundação de Apoio a Pesquisa do Estado de São Paulo (FAPESP) for to the financial support.

7. Ludwig HJ and Eyerer P. Influence of the processing conditions on morphology and deformation behavior of poly(butylene terephthalate) (PBT). Polymer Engineering and Science. 1988; 28(3):143-146. http://dx.doi.org/10.1002/ pen.760280304

8. Righetti MC, Di Lorenzo ML, Angiuli M and Tombari E. Structural reorganization in Poly(butylene terephthalate) during fusion. Macromolecules. 2004, 37(24):9027-9033. http:// dx.doi.org/10.1021/ma0492667

9. Di Lorenzo ML and Righetti MC. Morphological analysis of poly(butylene terephthalate) spherulites during fusion. Polymer Bulletin. 2004; 53(1):53-62. http://dx.doi.org/10.1007/ s00289-004-0315-8

10. Hong JS, Kim JL, Ahn KH and Lee SJ. Morphology Development of PBT/PE Blends during Extrusion and Its Reflection on the Rheological Properties. Journal of Applied Polymer Science. 2005; 97(4):1702-1709. http://dx.doi. org/10.1002/app.21695

11. Lumlong S, Kuboyama K, Chiba $\mathrm{T}$ and Ougizawa $\mathrm{T}$. Brittle-Ductile Transition in Reactive PBT/SAN Blends. Macromolecular Symposia. 2006; 233(1):17-25. http://dx.doi. org/10.1002/masy.200690014

12. Scaffaro R and La Mantia FP. Evolution of the Morphology and Characterization of Compatibilized PBT/EVA Blends Prepared by Reactive Extrusion. Macromolecular Chemistry and Physics. 2006; 207(3):265-272. http://dx.doi.org/10.1002/ macp. 200500491

13. Larocca NM, Hage E Jr and Pessan LA. Toughening of poly(butylene terephthalate) by AES terpolymer. Polymer. 2004; 45(15):5265-5277. http://dx.doi.org/10.1016/j. polymer.2004.05.056

14. Tomar N and Maiti SN. Thermal and Crystallization Properties of PBT/ABAS Blends. Journal of Applied Polymer 
Science. 2009; 113(3):1657-1663. http://dx.doi.org/10.1002/ app. 30172

15. Hage E Jr, Hale W, Keskula H and Paul DR. Impact modification of poly(butylene terephthalate) by ABS materials. Polymer. 1997; 38 (13):3237-3250. http://dx.doi.org/10.1016/ S0032-3861(96)00879-8

16. Hale W, Keskula H and Paul DR. Compatibilization of PBT/ ABS blends by methyl methacrylate-glycidyl methacrylateethyl acrylate terpolymers. Polymer. 1999; 40(2):365-377. http://dx.doi.org/10.1016/S0032-3861(98)00189-X

17. Hale W, Keskula H and Paul DR. Effect of crosslinking reaction and order of mixing on properties of compatibilizer PBT/ ABS blends. Polymer. 1999; 40(13):3665-3676. http://dx.doi. org/10.1016/S0032-3861(98)00602-8

18. Hale W, Pessan LA, Keskula H and Paul D.R. Effect of compatibilization and ABS type on properties of PBT/ABS blends. Polymer. 1999; 40(15):4237-4250. http://dx.doi. org/10.1016/S0032-3861(98)00670-3

19. Sun SL, Xu XY, Yang HD and Zhang HX. Toughening of poly(butylene terephthalate) with epoxyfunctionalized acrylonitrile-butadiene-styrene. Polymer. 2005; 46(18):7632-7643. http://dx.doi.org/10.1016/j. polymer.2005.06.011

20. Yao Z, Lin M, Zhou J, Wang H, Zhong W and Du Q. Influence of Epoxy Resin on the Morphological and Rheological Properties of PBT/ABS Blends Compatibilized by ASMA. Polymer Engineering and Science. 2007, 47(11):1943-1950. http://dx.doi.org/10.1002/pen.20913

21. Sun S, Tan Z, Zhou C, Zhang M and Zhang H. Effect of ABS Grafting Degree and Compatibilization on the Properties of PBT/ABS Blends. Polymer Composites. 2007; 28(4):484-492. http://dx.doi.org/10.1002/pc.20318

22. Utracki LA. Polymer Blends Handbook Vols. 1 and 2. Dordrecht: Kluwer Academic Publishers; 2002.

23. Pellow-Jarman M and Hetem M. Comparison of the thermal degradation products of poly(butylene terephthalate) and flame retardant poly(butylene terephthalate) formulations using a pyrolysis FTIR cell. Polymer Degradation and Stability. 1995; 47(3):413-421. http://dx.doi.org/10.1016/01413910(95)00006-2

24. Montaudo G, Puglisi C and Samperi F. Primary ThermalDegradation Mechanisms of PET and PBT. Polymer Degradation and Stability. 1993; 42(1):13-28. http://dx.doi. org/10.1016/0141-3910(93)90021-A

25. Botelho G, Queirós A, Liberal S and Gijsman P. Studies on thermal and thermo-oxidative degradation of poly(ethylene terephthalate) and poly(butylene terephthalate). Polymer Degradation and Stability. 2001; 74(1):39-48. http://dx.doi. org/10.1016/S0141-3910(01)00088-X

26. Samperi F, Puglisi C, Alicata R and Montaudo G. Thermal degradation of poly(butylene terephthalate) at the processing temperature. Polymer Degradation and Stability. 2004; 83(1):11-17. http://dx.doi.org/10.1016/S01413910(03)00167-8

27. GanPPandPaulDR. Interactionenergiesforblends basedonglycidyl methacrylate copolymers. Polymer. 1994; 35(16):3513-3524. http://dx.doi.org/10.1016/0032-3861(94)90917-2

28. Ambrósio JD, Larocca NM, Pessan LA and Hage E Jr. Influence of the process parameters of an intermeshing co-rotating twin screw extruder on the morphology and notched Izod impact strength of PBT/ABS/MGE blends. Polymer Engineering and Science. 2010; 50(12):2382-2391. http://dx.doi.org/10.1002/ pen. 21761

29. Kim KH, Isayev AI and Kwon K. Crystallization kinetics for simulation of processing of various polyesters. Journal of Applied Polymer Science. 2006; 102(3):2847-2855. http:// dx.doi.org/10.1002/app.24630

30. Jeong B, Xanthos M and Seo Y. Extrusion foaming behavior of PBT resins. Journal of Cellular Plastics. 2006; 42(2):165-176. http://dx.doi.org/10.1177/0021955X06060952

31. Pratt CF and Hobbs SY. Comparative study of crystallization rates by DSC and depolarization microscopy. Polymer. 1976; 17(1):12-16. http://dx.doi.org/10.1016/00323861(76)90146-4

32. Cheng SZD, Pan R and Wunderlich B. Thermal analysis of poly(butylene terephthalate) or heat capacity, rigid-amorphous content, and transition behavior. Macromolecular Chemistry and Physics. 1988; 189(10):2443-2458. http://dx.doi. org/10.1002/macp.1988.021891022

33. Yasuniwa M, Tsubakihara S, Ohoshita K and Tokudome S. X-ray studies on double melting behavior of poly(butylenes terephthalate). Journal Polymer Science Part B: Polymer Physics. 2001; 39(17):2005-2015. http://dx.doi.org/10.1002/ polb. 1176

34. Hage E Jr, Ferreira AS, Manrich S and Pessan LA. Crystallization behavior of PBT/ABS polymer blends. Journal of Applied Polymer Science. 1999; 71(3):423-430. http://dx.doi. org/10.1002/(SICI)1097-4628(19990118)71:3<423::AIDAPP8>3.0.CO;2-0

35. RuntJ,MileyDM,ZhangX, GallagherKP,McFeaters KandFisburn J. Crystallization of poly(butylene terephthalate) and its blends with polyarylate. Macromolecules. 1992; 25(7):1929-1934. http://dx.doi.org/10.1021/ma00033a015 